\title{
Fire Properties of Refuse-Derived Fuels: Measurements of Temperature Profiles and Mass Loss
}

\author{
SAMORN HIRUNPRADITKOON, BOGDAN Z. DLUGOGORSKI and ERIC M. KENNEDY \\ Process Safety and Environment Protection Research Group \\ School of Engineering \\ The University of Newcastle, Callaghan, NSW 2308, Australia \\ Email: Bogdan.Dlugogorski@newcastle.edu.au
}

\begin{abstract}
This investigation constitutes part of a larger study designed to obtain insights into fire properties of refusederived fuel (RDF). Several fires of densified RDF occurred in silos storing this material, giving us an impetus for this study, with the present investigation focusing on measuring temperature profiles and mass loss of RDF samples. A specialised sample holder was constructed to accommodate four fine thermocouples (76 $\mu \mathrm{m}$ in diameter), which facilitated the measurement of the temperature profiles within RDF samples undergoing oxidation and pyrolysis. An additional thermocouple was positioned at the base of the sample to verify the assumption of heat transfer in semi-infinite slab, prior to ignition. This assumption was applied previously within the context of the integral analysis to obtain the value of the effective thermal conductivity. The temperature profiles prior to ignition were combined with the measurements of the surface temperature collected by a pyrometer. Mass-loss measurements were also performed, but only after the onset of the flaming combustion, as a consequence of fluctuations induced by the changing flow field above the samples. A separate data-acquisition system was used to allow a faster sampling rate than $1 \mathrm{~Hz}$ permitted by the default setting of the cone calorimeter. The experiments determined the critical mass flux at extinction and identified three combustion regimes occurring in fires of RDF-type materials: flaming combustion; a transition regime involving simultaneous flaming combustion and char pyrolysis; and char pyrolysis. These measurements were consistent with results of the earlier fire experiments performed in the cone calorimeter.
\end{abstract}

KEYWORDS: refuse-derived fuels; ignition; extinction; cone calorimeter, fire properties

\section{INTRODUCTION}

Municipal solid waste (MSW) has been utilised for waste-to-energy conversion to produce steam and operate power-generating facilities since 1980s [1]. Energy recovery processes are intended to achieve resource conservation by retrieving the energy constrained in the combustible fraction of MSW. MSW can provide energy for heating, producing steam, and generating electricity, by being co-combusted alone or with coal and other fuels in multifuel boilers or power plants. Prior to burning in a waste-to-energy power plant, MSW is initially processed for removal of large, non-combustible materials, such as masonry or metals. The remaining material is then shredded and mechanically separated into non-combustible and combustible fractions. The latter, termed refuse-derived fuel (RDF), are then shredded to small sizes and densified to form pellets, ready for use. RDF contains high calorific heat value components such as wood, paper and plastic. Non-densified samples of RDF, as those studied in the present investigation, constitute a group of heterogenous materials characterised by substantial void fraction.

The purpose of this contribution is to examine (i) the temperature profiles within beds of non-densified RDF, and (ii) mass changes of RDF samples as a result of pyrolysis and char oxidation. The former aims to confirm the assumptions of an earlier ignition model [2], whereas the latter serves to obtain a critical mass flux of pyrolysates produced by the burning material at extinction of the flaming combustion. The measurements were performed in mass-loss (part i) and cone (part ii) calorimeters, with major modifications performed to both instruments, including adaptations of the sample holder and the data acquisition system.

Temperature measurements are divided into the pre- and post-ignition periods. This is done for convenience in reporting the experimental data and to highlight the differences in the pre- and post-ignition heat transfer regimes in the RDF samples. During the pre-ignition period, a steep temperature profile develops in the material near its top boundary, although within the sample itself the temperature remains 
unchanged. The pre-ignition measurements allow one to confirm the thermally-thick approximation of our previous analysis [2], to provide a complete picture of heat transfer in RDF samples prior to ignition.

Following ignition, as a consequence of the attrition of the RDF material, the top thermocouples become progressively exposed in the gas phase and may no longer track the material's true temperature. Later in the burning process, following the cessation of flaming combustion, the thermocouples remaining in the material show a substantial, though slow, increase in temperature. This effect occurs as a consequence of the shift in the kinetic regime in the samples, from endothermic pyrolysis reactions to the exothermic char oxidation.

The temperature results are complemented by measurements of the mass-loss rate, which reflect the volume-average rate of pyrolysis and char oxidation in the RDF samples. These measurements are performed for three sample densities (consistently with reference [2]), but only for the samples of $40 \mathrm{~mm}$ in thickness, to circumvent laboratory difficulties encountered in experiments with thinner samples. The mass-loss measurements are converted to mass-flux data by differentiating the mass-loss curves and then dividing the results by the area of the opening of the sample holder. This permits one to obtain estimates of critical mass fluxes at ignition and extinction of the RDF material.

\section{EXPERIMENTAL}

\section{Material}

The surrogate RDF developed for the present study corresponds to typical municipal solid waste collected in the city of Newcastle, in the state of New South Wales in Australia. The surrogate RDF incorporates shredded newspaper, wood, grass and plastic bags, with small amounts of sugar and bread. About $95 \%$ of the material passes through $50 \mathrm{~mm}$ square screens, as required by ASTM E828 standard for RDF-3 specification. Reference [2] contains detailed description of the composition and preparation of the surrogate RDF.

The material can ignite within a few seconds, especially at higher heat fluxes, such as at $40 \mathrm{~kW} \mathrm{~m}^{-2}$ [2]. The fire grows rapidly to attain the peak heat release rate of $110-165 \mathrm{~kW} \mathrm{~m}^{-2}$. The material is characterised by the apparent critical heat flux, the apparent pyrolysis temperature and the effective thermal conductivity of 9-10 $( \pm 2) \mathrm{kW} \mathrm{m}{ }^{-2}, 280-310( \pm 30){ }^{\circ} \mathrm{C}$, and 0.4-0.7 $( \pm 0.3) \mathrm{W} \mathrm{m}^{-1} \mathrm{~K}^{-1}$, respectively, depending on the material density. [2] The effective heat of combustion of the RDF is estimated as $15.3 \mathrm{MJ} \mathrm{kg}^{-1}$. The material produces $1 \mathrm{~kg}$ of $\mathrm{CO}$ per $18 \mathrm{~kg}$ of dried RDF, mostly during smouldering phase after the extinguishment of the flaming combustion. [2]

\section{Measurements of Temperature Profiles}

The experiments to measure the evolution of the temperature profiles in the samples were conducted in a mass-loss calorimeter [3]. The device consisted of a heating element, with its temperature regulated by the Eurotherm 847 controller, and a strain gauge for obtaining the mass-loss measurements. The sample holder was of standard size, $100 \times 100 \mathrm{~mm}$ in area, $50 \mathrm{~mm}$ in height, with an exposed surface area of $0.0088 \mathrm{~m}^{2}$, and operated in the horizontal orientation. The sample holder was instrumented with five chromel-alumel (Type K) thermocouples, all made of wires of $76 \mu \mathrm{m}$ in diameter. Holes were drilled through the holder's walls to allow the top four thermocouples to be positioned at fixed locations 3, 8, 13 and $23 \mathrm{~mm}$ below the initial surface of the samples, as illustrated schematically in Fig. 1. Note that as the sample's surface regressed due to burning, the two top thermocouples could become exposed and broken. The fifth thermocouple was placed at the bottom of the sample holder to measure the temperature at the base of the sample.

Tubes made of alumina (o.d. $1.6 \mathrm{~mm}$, i.d. $0.79 \mathrm{~mm}$ ) were passed through the holes, providing insulation between the thermocouple wires and the sample holder. Note that a double-hole alumina insulator (o.d. 1.6 $\mathrm{mm}$, i.d. $0.40 \mathrm{~mm}$ ) was used for the bottom thermocouple. Within the central portion of the thermocouple wires, about $2.5 \mathrm{~cm}$ on each side of the thermocouple junction, the thermocouple wires were not insulated by the alumina tubes. This was done to minimise the thermal inertia of the thermocouple assembly and to avoid conduction losses between the thermocouple junction and the alumina insulator. The photograph in Fig. 2 demonstrates the arrangement of the insulators and the thermocouple wires. Because of the fine thickness of the wires, the thermocouples are difficult to see in the photograph. 
All thermocouples were connected to two perspex blocks on one side of the sample holder, with each perspex block consisting of eight pairs of terminal strips of which only five were used. The perspex blocks were protected from the thermal radiation emitted by the cone by a radiation shield. Figures 6.3-5 of reference [3] illustrate the details of this arrangement.

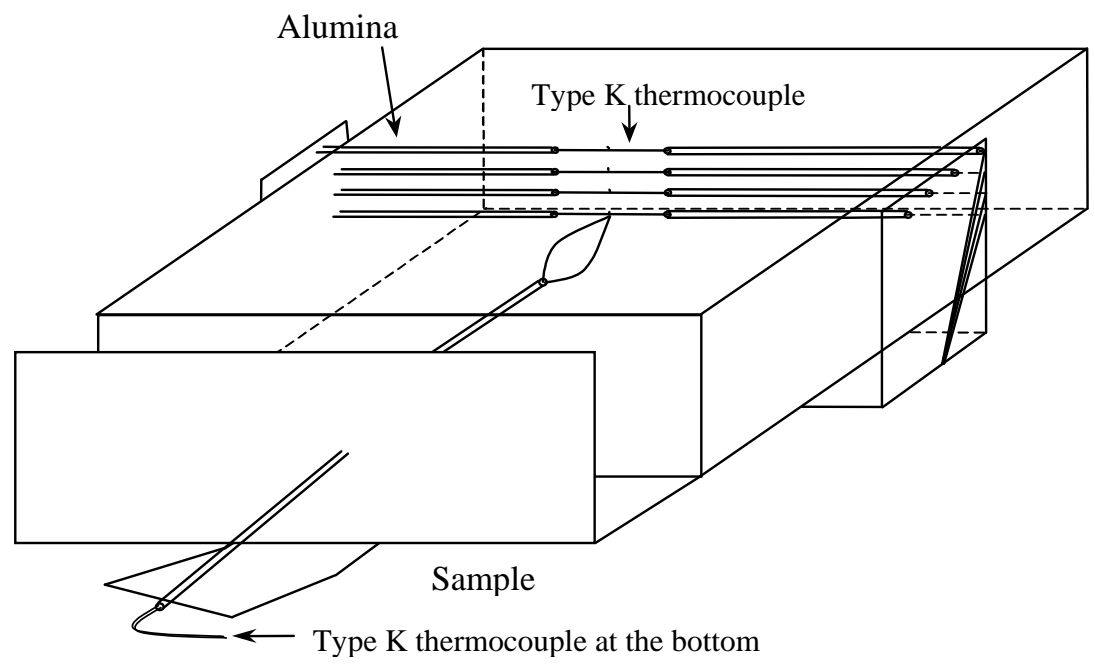

Fig. 1. Schematic diagram of the modified sample holder with the thermocouple assembly.

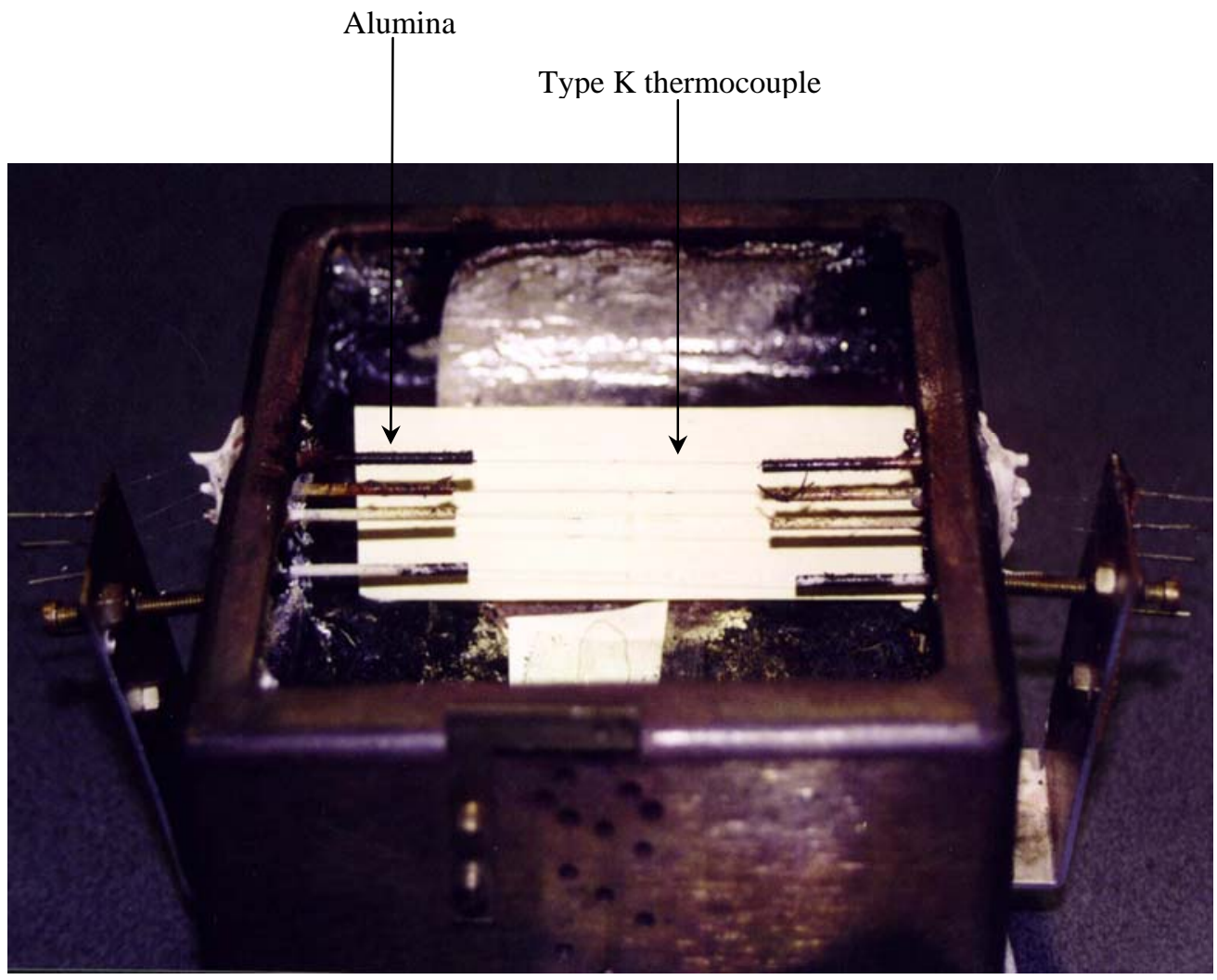

Fig. 2. Photograph of the thermocouple assembly. 
For the experiments conducted prior to ignition, the analogue signal of the five thermocouples was digitised at the frequency of $200 \mathrm{~Hz}$ (5 ms intervals). The data collection system consisted of a PC computer equipped with a PCI-6024E data acquisition card and running the Labview software. This setup enabled the simultaneous recording of the thermocouples within the RDF samples as well as those of the samples' surface temperature performed by a pyrometer [3].

Following ignition, flames could damage the pyrometer and the measurement of the surface temperature could not be continued. Thus, after ignition, only the temperature histories inside the samples were recorded. In the post-ignition region, the experimental runs were much longer, in the order of $500 \mathrm{~s}$, as compared to $20 \mathrm{~s}$ prior to ignition. Although the same data acquisition system was deployed in the postignition series of experiments, the frequency of sampling was reduced to $10 \mathrm{~Hz}$. The measurement of the temperature profiles continued for about 150-200 s after completion of the flaming combustion. For example, at the irradiance level of $20 \mathrm{~kW} \mathrm{~m}^{-2}$, the flame extinguished at between 200 and $250 \mathrm{~s}$, and the data collection was continued until $400 \mathrm{~s}$. At the irradiance level of $45 \mathrm{~kW} \mathrm{~m}^{-2}$, the flame extinguished between 400 and $450 \mathrm{~s}$ necessitating longer experimental runs, up to $600 \mathrm{~s}$ in duration.

\section{Measurements of Mass Flux and Mass Loss}

The mass-loss results were obtained from model-fire experiments conducted in the cone calorimeter. The mass flux rates, that is, the mass change per unit surface and per unit time, correspond to the slope of the mass loss curve divided by the surface area of the sample holder $\left(0.0088 \mathrm{~m}^{2}\right)$. These results afford investigating the pyrolysis rates during flaming combustion and permit estimating the rates of char oxidation during smouldering. It will be evident in the next section that, the combustion of thicker and more dense RDF samples under fire conditions leads to the emergence of a transitional period, characterised by simultaneous flaming combustion and char oxidation. In this transitional period, the results presented here provide an estimate of the overall mass loss of an RDF sample.

Experiments were performed under three typical irradiance levels (30, 40 and $50 \mathrm{~kW} \mathrm{~m}$ ), for three nominal sample densities (37.5, 50 and $62.5 \mathrm{~kg} \mathrm{~m}^{-3}$ ) characteristic of non-densified RDF, and for one sample thickness $(40 \mathrm{~mm})$. The signal from the strain gauge was logged by a PCI-6024E/Labview 5.0 system at $10 \mathrm{~Hz}$. The measurements were collected over $800 \mathrm{~s}$ during each experiment.

\section{RESULTS AND DISCUSSION}

\section{Temperature Profiles Prior to Ignition}

Figures 3 and 4 illustrate replicated temperature profiles within the RDF material at ignition (sample thickness $L=40 \mathrm{~mm}$, and density $\rho=50 \mathrm{~kg} \mathrm{~m}^{-3}$ ) for the irradiance levels of 20 and $45 \mathrm{~kW} \mathrm{~m}^{-2}$. At each irradiance level, at least four replicates were obtained. The time to ignition $\left(t_{i g}\right)$ and the surface temperature at ignition $\left(T_{i g}\right)$ for each replicate are tabulated in the inserts in Figs. 3 and 4 , together with the typical error bars in the thermocouple measurements. The temperatures at the top of each sample $(L=0)$ are those measured with the pyrometer (see Chapter 5 of reference [3]). One can readily notice from these figures that the thermally-thick assumption applies well prior to ignition, even for the samples of $12.5 \mathrm{~mm}$ in thickness. This means that a thermal wave propagating into the material does not encounter the bottom boundary and the material, for the purpose of the heat-transfer calculations, can be considered as a semiinfinite slab, at all times before ignition, in accordance with the previous investigation [2].

Figure 3 shows that a significant scatter in the experimental results occurs at measuring positions of 3 and 8 $\mathrm{mm}$ inside the material. The scatter in the data obtained at an irradiance of $45 \mathrm{~kW} \mathrm{~m}$ is not as apparent (Fig. 4). Note that at $20 \mathrm{~kW} \mathrm{~m}{ }^{-2}$ it takes 6-8 times as long for a sample to ignite as it does for samples exposed to an irradiance of $45 \mathrm{~kW} \mathrm{~m}^{-2}$. It is possible that the heterogeneous nature of the material leads to a temperature field which depends locally on the material composition. The heterogeneities may include different types of materials, different particle sizes and different void fractions.

\section{Temperature Histories}

The results obtained for the temperature histories within the RDF samples are shown in Figs. 5 and 6 for irradiance levels of 20 and $45 \mathrm{~kW} \mathrm{~m}^{-2}$, respectively. The temperature measurements in these experiments were affected by electromagnetic interference (spikes) induced by the cone calorimeter. The spikes were 
manually removed to generate smooth temperature histories, corrected for electromagnetic interference. The current experimental measurements are presented in terms of the temperature evolution with time, at each measuring station. Because of this consideration, these measurements are denoted as the temperature histories rather than the temperature profiles. The shapes of the temperature histories at various stations are similar to those published by other researchers for wood, e.g. by Kashiwagi et al. [4].

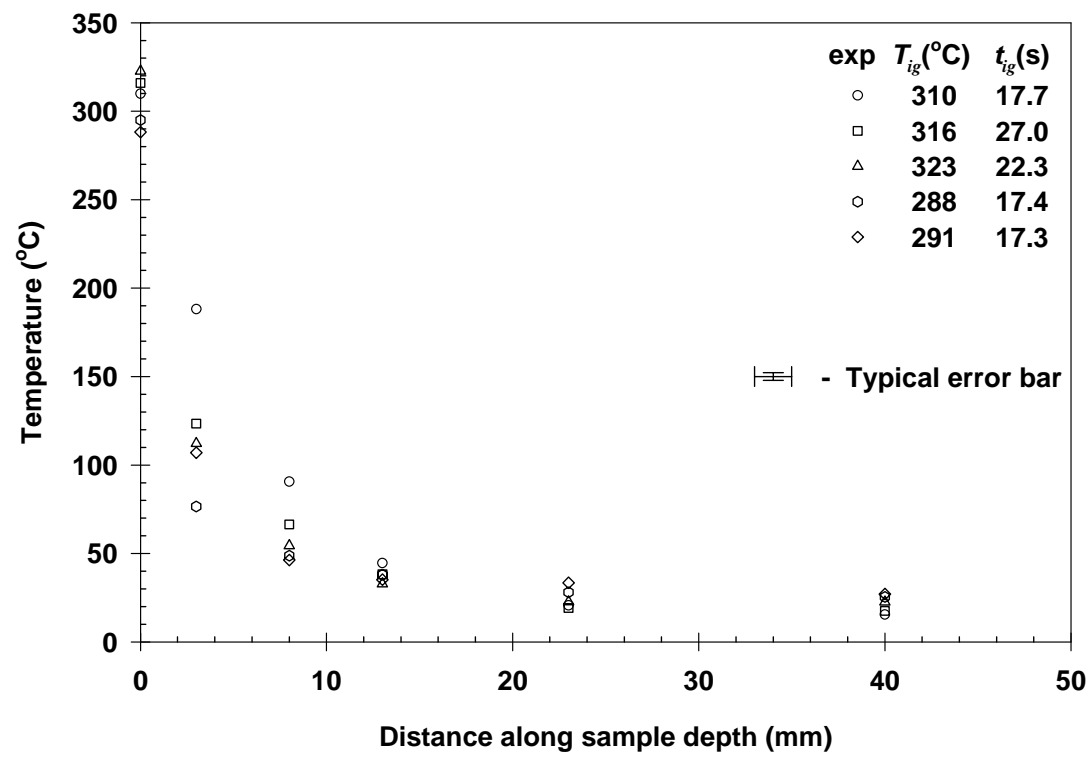

Fig. 3. Replicates of the temperature profile at ignition for oven dried surrogate RDF, $L=40 \mathrm{~mm}, \rho=50 \mathrm{~kg}$ $\mathrm{m}^{-3}$ and $\dot{q}^{\prime \prime}=20 \mathrm{~kW} \mathrm{~m}{ }^{-2}$.

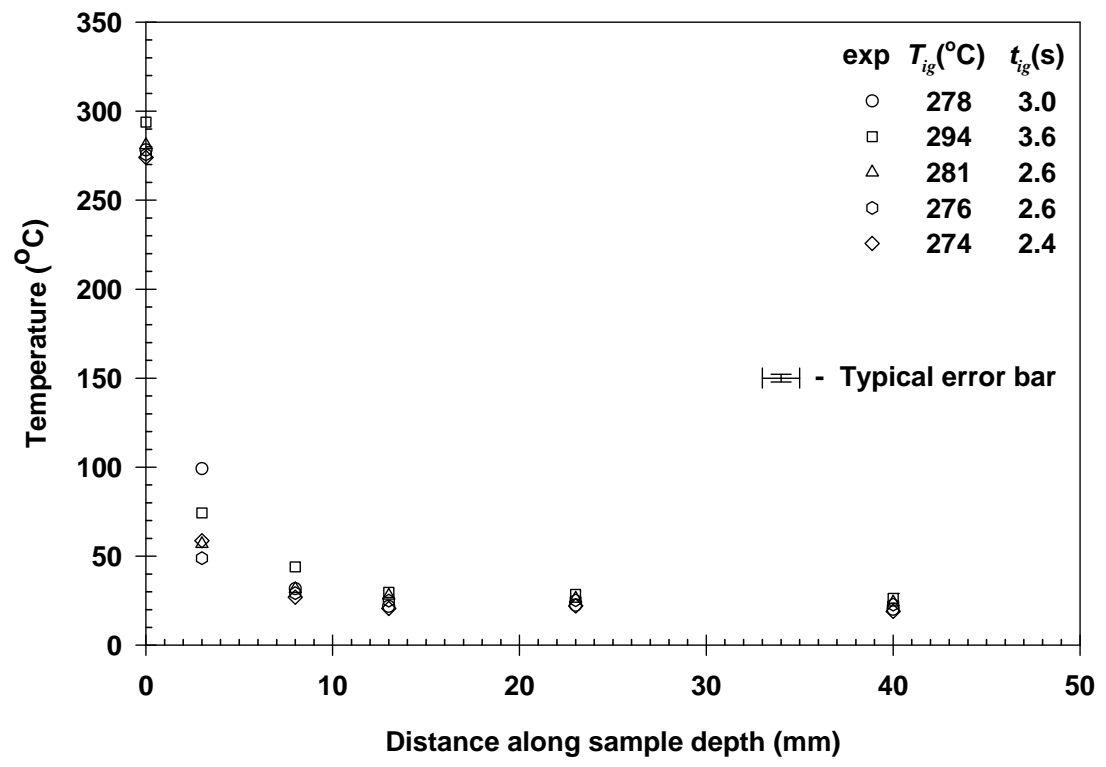

Fig. 4. Replicates of the temperature profile at ignition for oven dried surrogate RDF, $L=40 \mathrm{~mm}, \rho=50 \mathrm{~kg}$

$$
\mathrm{m}^{-3} \text { and } \dot{q}^{\prime \prime}=45 \mathrm{~kW} \mathrm{~m}^{-2} \text {. }
$$

The specimens burned more intensely at the edges than at the centre of the sample, leading to the sample surface receding faster at the edges. This phenomenon caused tensioning of the thermocouple wires and 
eventually contributed to the breakage of thermocouples 1 and 2, as illustrated in Fig. 6. Figure 7 and 8 plot the temperature histories. The measurements in Figs. 7 and 8 were obtained in separate experiments from those of Figs. 5 and 6. Note that the surface temperature histories illustrated in Figs. 7 and 8 are derived from the pyrometer readings of Chapter 5 of reference [3].

It is evident that very little heating takes place within the specimens prior to ignition, and the heat wave propagates substantially into the material only after the ignition. Before ignition, the temperature rise close to the surface of the sample may be in part due to the exothermic reactions between oxygen and the carbonaceous components of RDF, as reported for wood by Kashiwagi et al. [4].

The temperature profiles within the samples (compare Figs. 7 and 8 at the same instant) depend on the incident heat flux. High irradiances result in more elevated temperatures, as a consequence of increased heat input into the samples and more rapid oxidation of char. The effect of char oxidation can be seen at longer times by comparing the temperature histories at the lowest measuring station in Figs. 5 and 6. But char oxidation can also increase the temperature at other locations closer to the surface of the sample [5], and result in emission of carbon monoxide. The latter observation is consistent with the measurements of the emission of carbon monoxide reported previously [2].

A noticeable temperature plateau around $100{ }^{\circ} \mathrm{C}$ can be seen in Figs. 5 and 6 for both the low and high heat fluxes imposed on surfaces of surrogate RDF. This plateau is found at locations of 23 and $40 \mathrm{~mm}$ from the sample surface at both irradiance levels of 20 and $45 \mathrm{~kW} \mathrm{~m}^{-2}$. Although the samples were initially dry, they are very hygroscopic and might have accumulated moisture when they were charged into the sample holder. The plateaux were not observed at stations 1-3 (Figs. 5 and 6), which is consistent with the observation of Kashiwagi et al. [4] who noted that near the sample surface the heating rate is too fast for this plateau to become noticeable. It is also reasonable to suggest that the moisture present at the bottom of the sample migrated there from the pyrolysing RDF close to the surface, early in the combustion process. Such a phenomenon was reported by Dlugogorski et al. [6] for the combustion of cardboard under fire conditions.

\section{Mass Flux and Mass Loss}

The experimental results are summarised in Fig. 9 in terms of mass loss and in Fig. 10 in terms of mass flux. The data are presented only after the onset of flaming combustion. Because of the rapid mass fluctuations induced by the expanding flame at the point of ignition, it was not possible to obtain reliable results prior to ignition. For this reason, these measurements are not included in Fig. 9 and 10.

It can be readily seen that, following ignition, the sample mass decreases rapidly due to pyrolysis, especially for samples of the lowest density $\left(37.5 \mathrm{~kg} \mathrm{~m}^{-3}\right)$; see Fig. 9. The rate of mass change (mass flux) declines as well (Fig. 10), owing to the increasing limitations in mass and heat transfer within the specimens due to the accumulation of char and longer path for diffusion of pyrolysates. Note that the mass flux declines monotonically following ignition. This is consistent with the oxygen-consumption measurements [2] that show no second peaks in the curves of heat release rate. After the cessation of the flaming combustion, the sample mass continues to decline, but at a much slower rate, indicating char oxidation.

For each experiment, the mass of the sample at near ignition and at extinction is indicated in the legend to Fig. 9. The mass fluxes at these two points are shown in the legend to Fig. 10. With respect to the results shown in the legend to Fig. 9, the percentage of the material removed prior to extinction is approximately constant (68\%), and no trends can be discerned as to the influence of sample density or the irradiance level, above the background level of the experimental scatter. This means that the mass released by RDF specimens prior to extinction is limited by the total amount of fuel available in the samples. This is consistent with the previous measurements [2].

On the other hand, the mass flux after at the point of ignition shows an upward trend with increasing incident radiative heat flux (compare the values of mass flux in Fig. 10 at $t=0$ among various heat fluxes). This is why the peak heat release rate, which occurs shortly after ignition of the RDF samples, tends to increase with the incident radiative flux [2]. The mass flux at the point of extinguishment of the flaming combustion decreases with increasing sample density and increasing heat flux. Although the latter observation is only evident for the two denser sample types, it is consistent with the previous results [2]. 


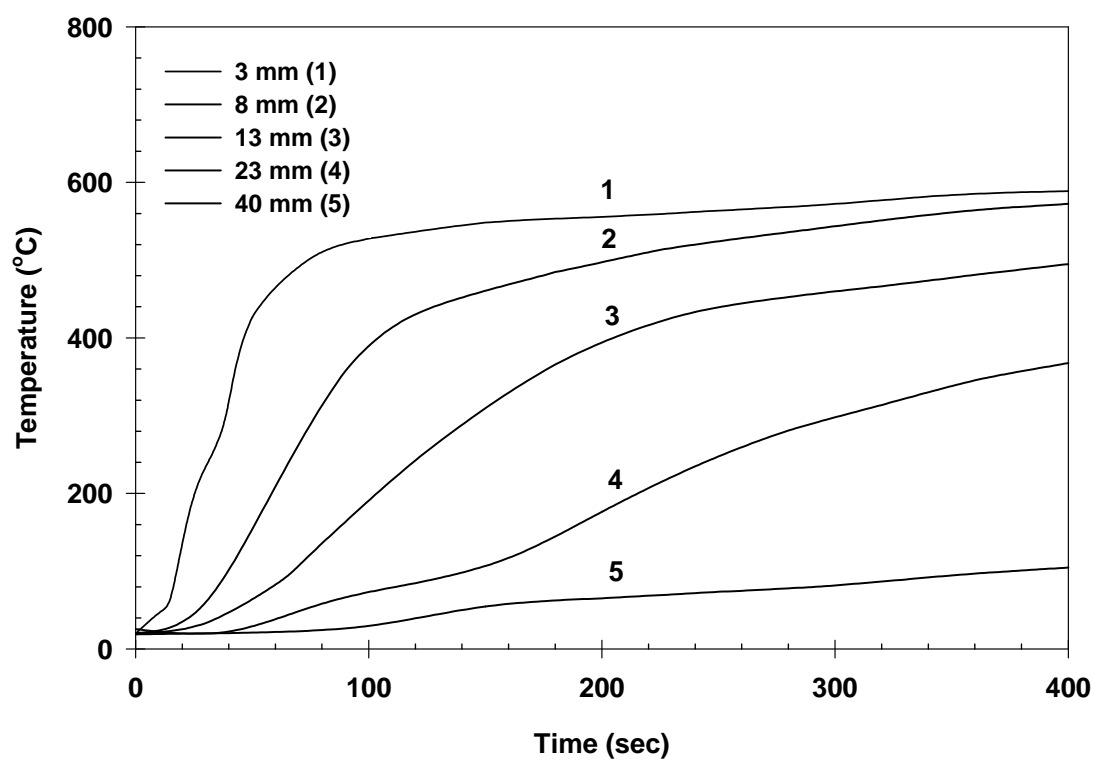

Fig. 5. Transient temperature distributions of $40 \mathrm{~mm}$ in thickness and $50 \mathrm{~kg} \mathrm{~m}^{-3}$ in density of oven dried surrogate RDF samples, at an irradiance level of $20 \mathrm{~kW} \mathrm{~m}^{-2}$.

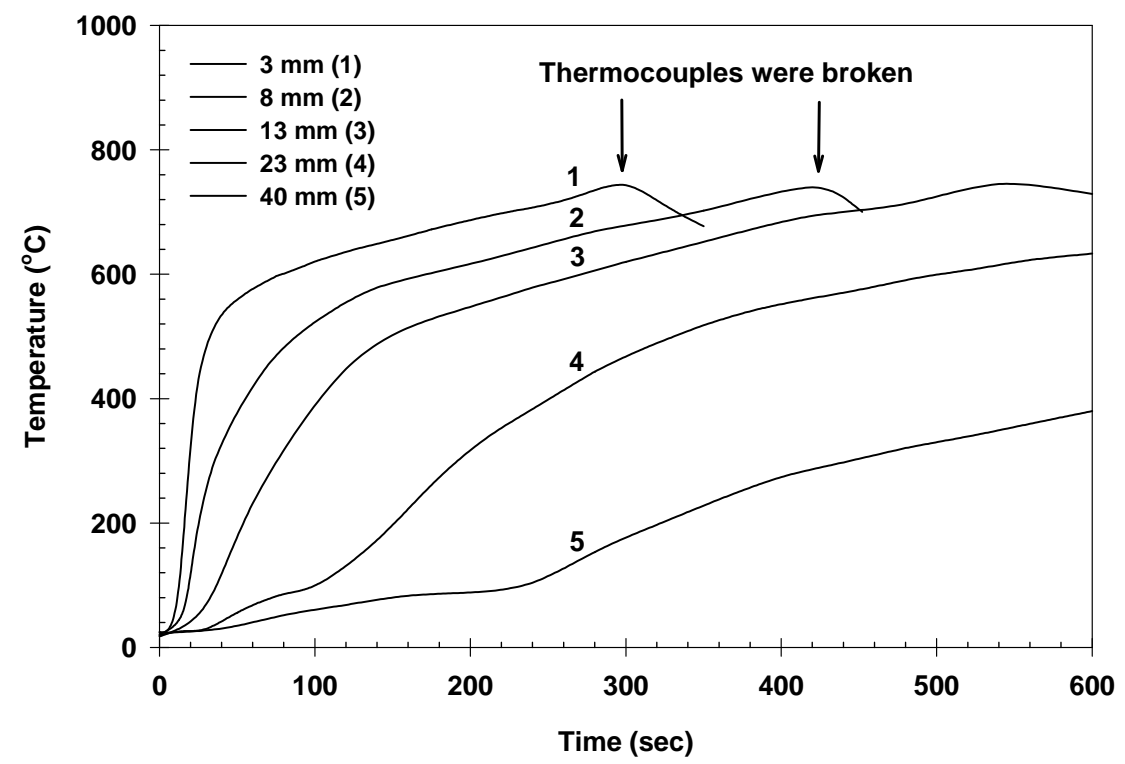

Fig. 6. Transient temperature distributions of $40 \mathrm{~mm}$ in thickness and $50 \mathrm{~kg} \mathrm{~m}^{-3}$ in density of oven dried surrogate RDF samples, at an irradiance level of $45 \mathrm{~kW} \mathrm{~m}^{-2}$.

In several experiments, especially with higher-density and thicker samples, we observed that the periods of flaming and smouldering combustion were not well separated by a point of flame disappearance. Rather, toward the end of the flaming combustion, the flames remained anchored only over part of a specimen's surface allowing oxygen to diffuse to the surface of the remaining part of the sample. In thinner and less dense samples, this did not happen resulting in more rapid extinguishment, once an insufficient quantity of the decomposition products was delivered to the gas phase to sustain flaming combustion. See for example Fig. 11, reproduced here from reference [2], in which the flaming and smouldering combustion are well distinguished by different slopes in the HRR curves. Now observe in Fig. 12, also extracted from reference [2], for $L=40 \mathrm{~mm}$, an intermediate stage at between 150 to $250 \mathrm{~s}$, with both pyrolysis and char oxidation 
taking place at the same time. This intermediate stage occurs only for thicker and denser samples. If extinguishment arises in the regime where the contribution of char oxidation to the total heat release rate is small, the mass flux at extinction is constant, around 1.5-1.9 $\mathrm{g} \mathrm{m}^{-2} \mathrm{~s}^{-1}$, with the variation due to the experimental scatter. However, if extinguishment takes place in the regime characterised both by pyrolysis and char oxidation, the critical mass flux at extinction varies over a wider range, between 0.8 and $1.5 \mathrm{~g} \mathrm{~m}^{-2}$ $\mathrm{s}^{-1}$.

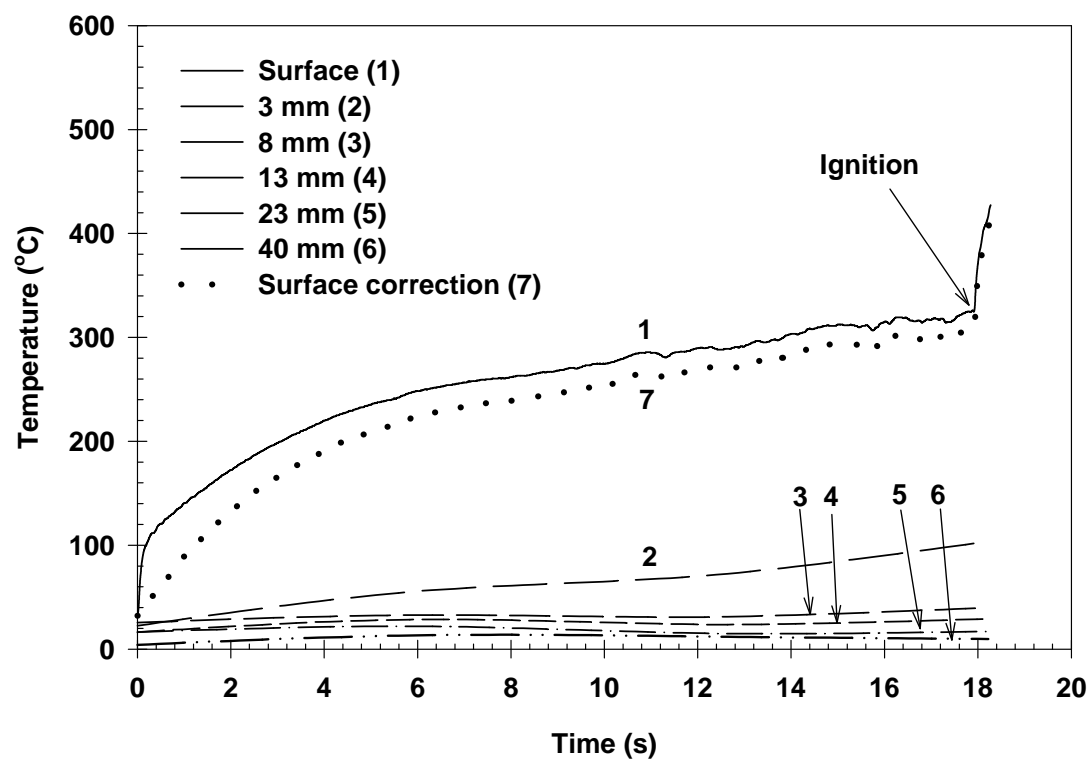

Fig. 7. Temperature histories recorded by the pyrometer and temperature inserted within oven dried surrogate RDF samples, at $L=40 \mathrm{~mm}, \rho=50 \mathrm{~kg} \mathrm{~m}^{-3}$ and $\dot{q}^{\prime \prime}=20 \mathrm{~kW} \mathrm{~m}^{-2}$.

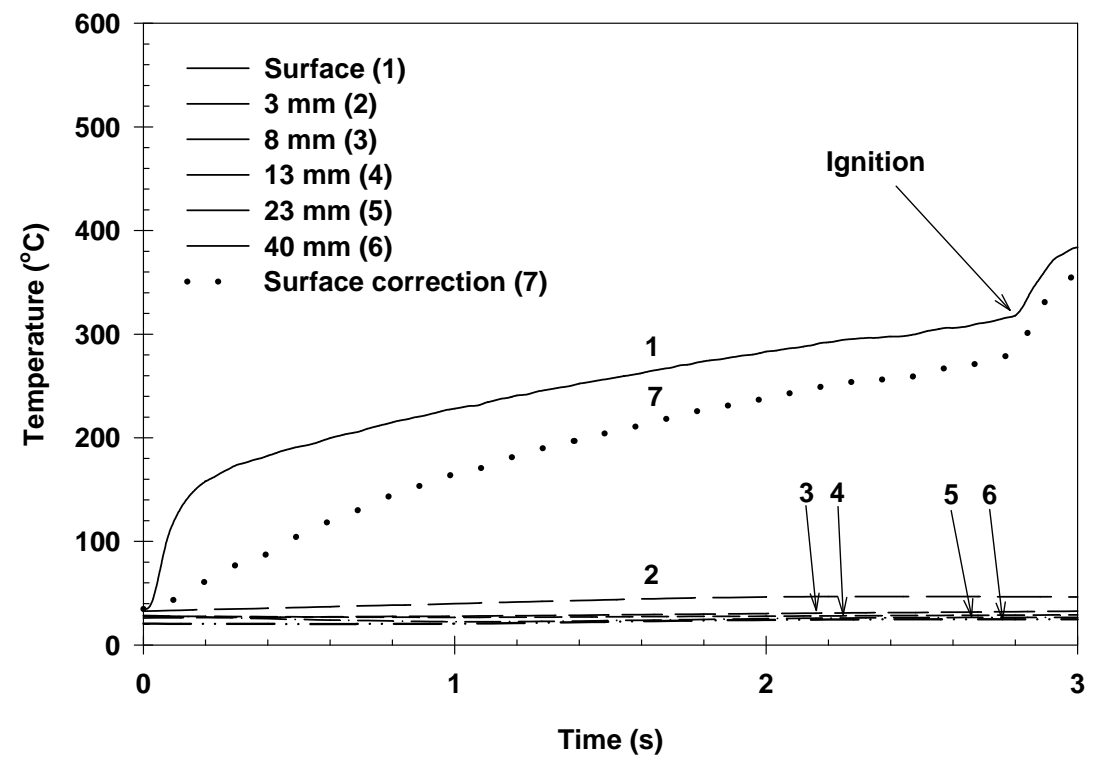

Fig. 8. Temperature histories recorded by the pyrometer and temperature inserted within oven dried surrogate RDF samples, at $L=40 \mathrm{~mm}, \rho=50 \mathrm{~kg} \mathrm{~m}^{-3}$ and $\dot{q}^{\prime \prime}=45 \mathrm{~kW} \mathrm{~m}^{-2}$. 


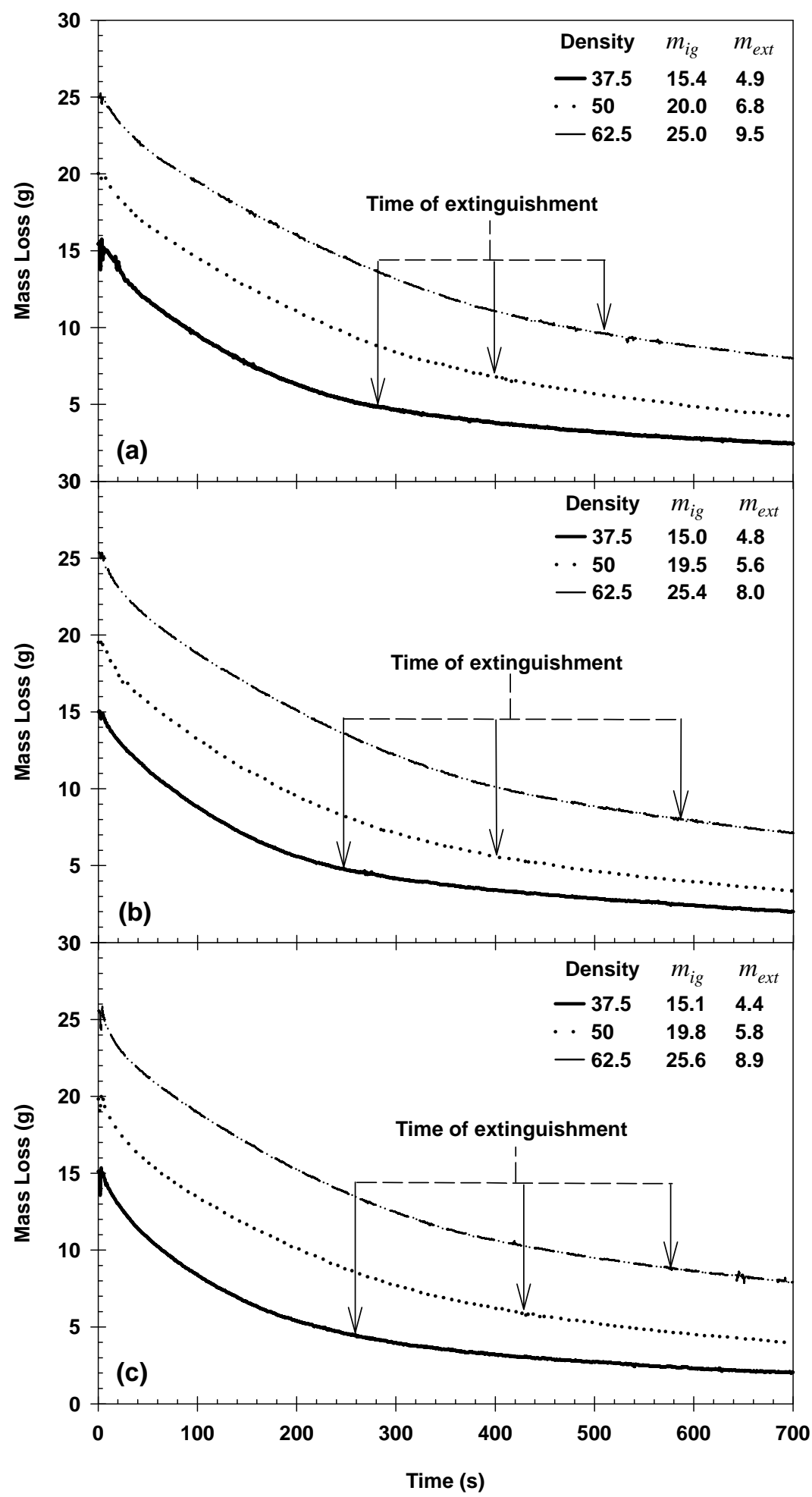

Fig. 9. Mass loss histories of oven surrogate dried RDF, starting from the time of ignition, for three different densities at $40 \mathrm{~mm}$ in thickness and the three different irradiance levels: (a) $30 \mathrm{~kW} \mathrm{~m}^{-2}$; (b) $40 \mathrm{~kW}$ $\mathrm{m}^{-2}$; (c) $50 \mathrm{~kW} \mathrm{~m}^{-2}$. 


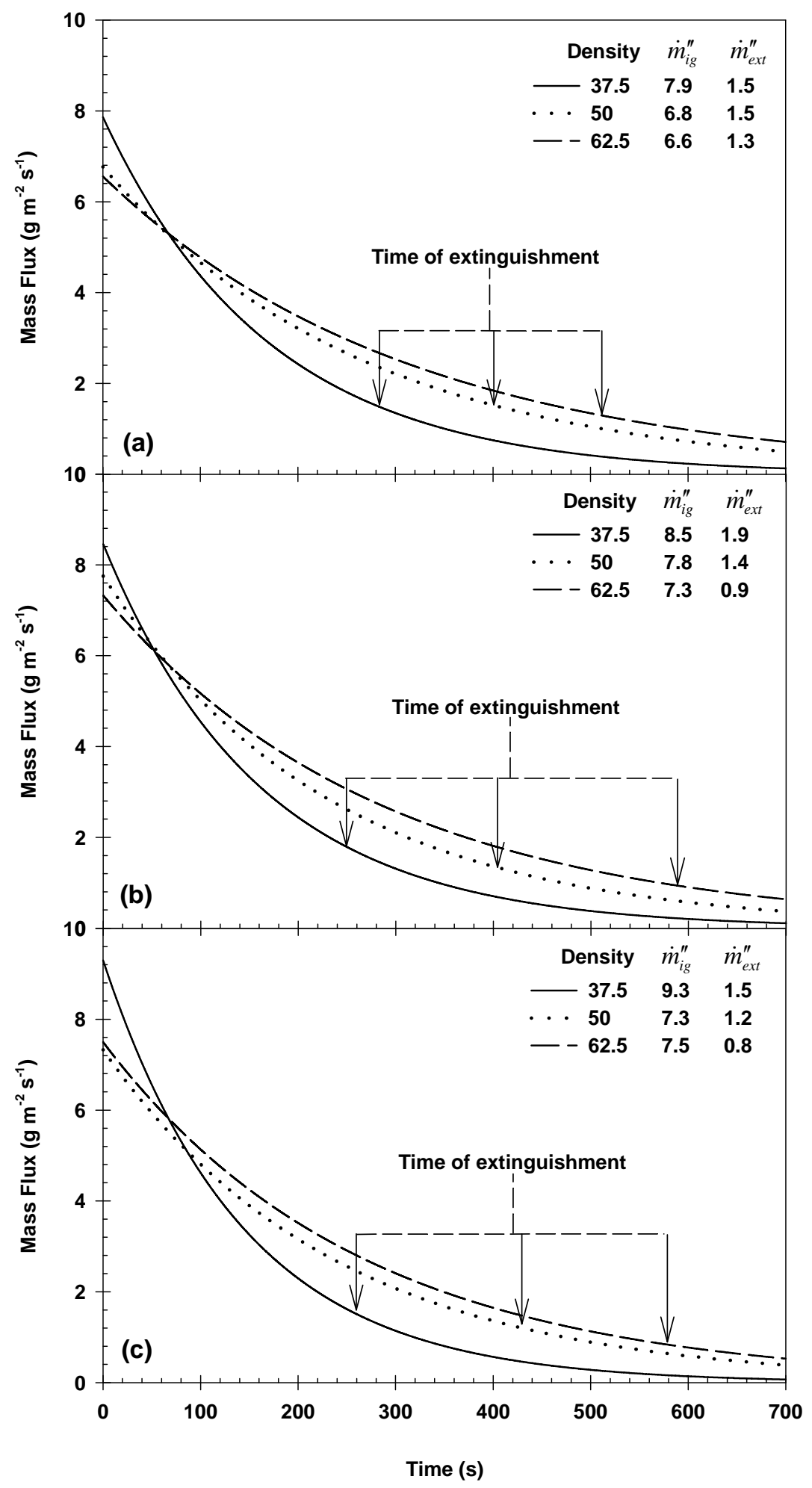

Fig. 10. Mass flux histories of oven dried surrogate RDF, starting from the time of ignition, for three different densities at $40 \mathrm{~mm}$ in thickness and the three different irradiance levels: (a) $30 \mathrm{~kW} \mathrm{~m}^{-2}$; (b) $40 \mathrm{~kW}$ $\mathrm{m}^{-2}$; (c) $50 \mathrm{~kW} \mathrm{~m}^{-2}$. 


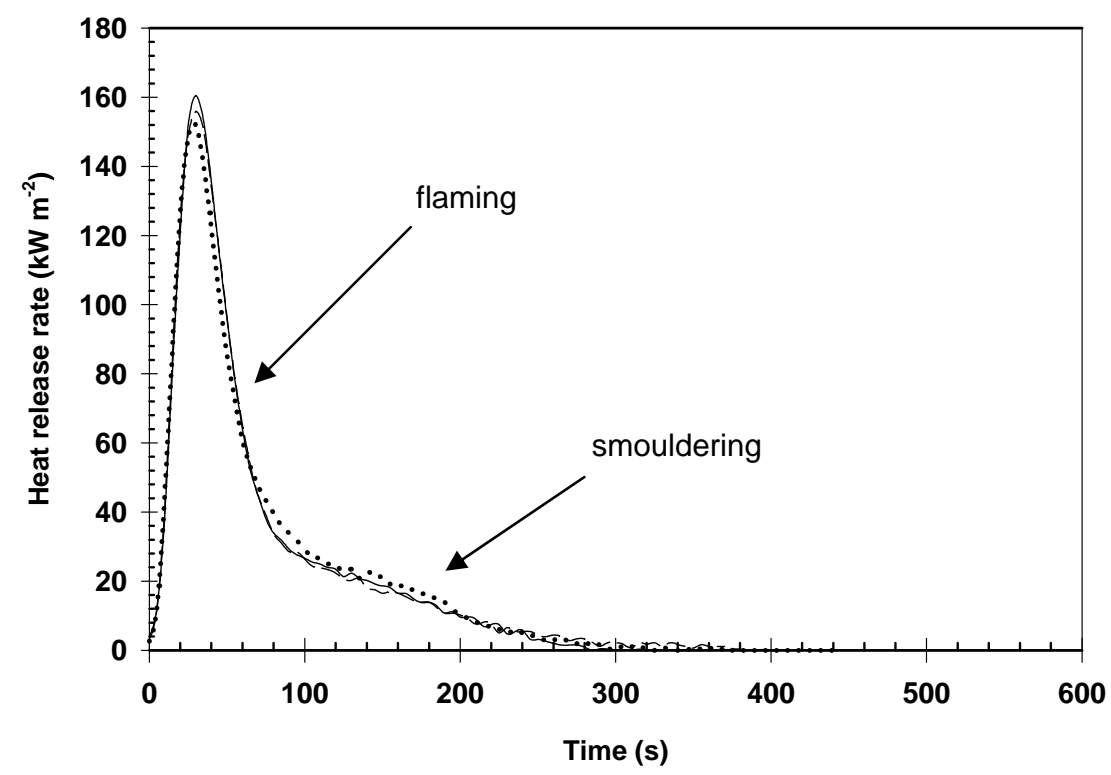

Fig. 11. Heat release rate from three replicated experiments of oven dried surrogate RDF $12.5 \mathrm{~mm}$ in thickness and $37.5 \mathrm{~kg} \mathrm{~m}^{-3}$ in density, at an irradiance of $40 \mathrm{~kW} \mathrm{~m}^{-2}$. [2]

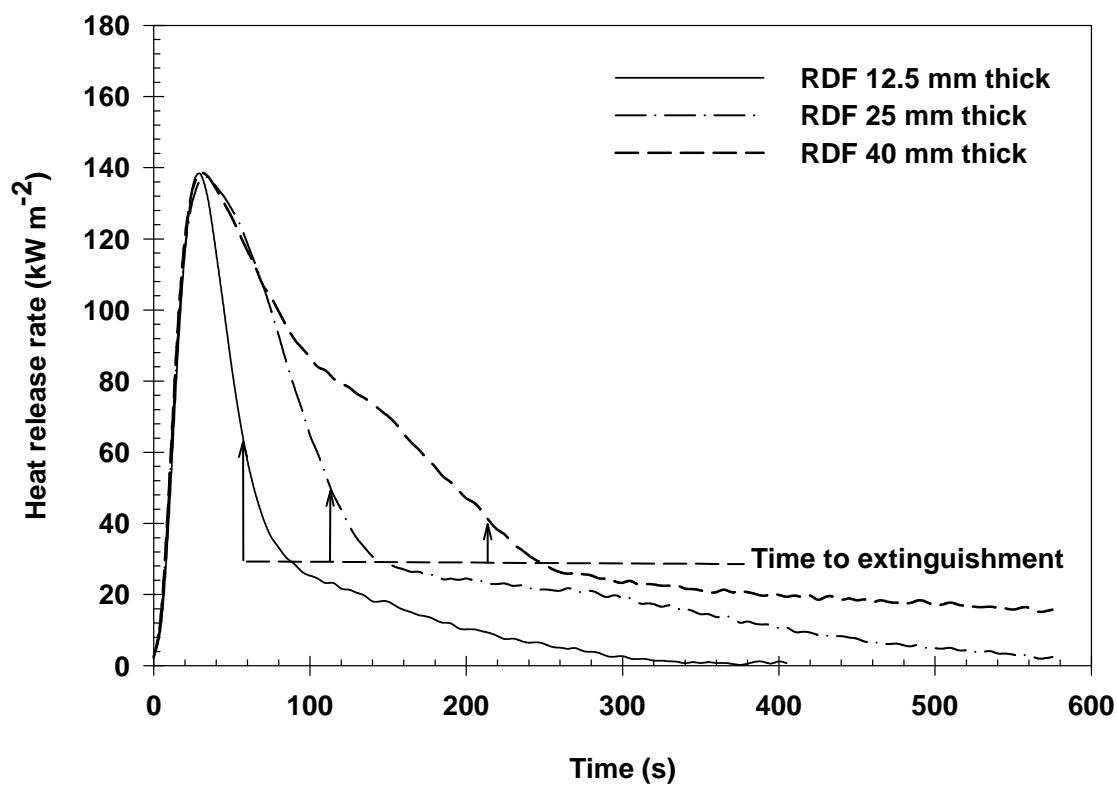

Fig. 12. Heat release rate for three different thicknesses of oven dried surrogate RDF $37.5 \mathrm{~kg} \mathrm{~m}^{-3}$ density at an irradiance level of $40 \mathrm{~kW} \mathrm{~m}^{-2}$. [2]

Finally, attention must be drawn to an inconsistency in the extinguishment times between the results presented in Figs. 9 and 10, and in previous work [2]. As opposed to thermoplastic polymers and solid wood, the point of extinguishment of RDF samples cannot be readily discerned, because of the overlap between the flaming and smouldering combustion regimes. For this reason, identification of the point of extinguishment depends on the operator, and even for the same operator the results may still be inconsistent if they were collected over a long period of time. From this perspective, the experiments reported in reference [2] and the present article were performed two years apart. 


\section{CONCLUSIONS}

In this contribution we presented experimental measurements of (i) the temperature profiles and temperature histories before and after ignition, as well as (ii) mass loss and mass flux results of RDF samples exposed to irradiant fluxes in the cone calorimeter. The temperature profiles prior to ignition display a steep temperature rise near the material's surface and very little temperature variation inside the specimens. This proves the validity of the conjecture that RDF can be considered thermally thick as it was assumed previously, within the context of the integral analysis [2]. Heterogeneities in RDF, such as different type of materials, different particle sizes and different (local) void fractions, lead to variation in the temperature profiles observed in replicated experiments. The temperature histories in the samples are similar in shape to those published in the literature, which were interpreted by other researchers to indicate the presence of exothermic reactions occurring prior to ignition. The imposed radiative heat flux influences the temperature histories inside RDF samples, and affects the rate of the pyrolysis and especially the rate of the char-oxidation reactions.

As a consequence of fluctuations in the readings of the strain gauge, no mass loss results (pre-ignition oxidation and pyrolysis) were derived from the measurements prior to ignition. After ignition, both massloss and mass-flux curves decrease monotonically. This observation is consistent with the previous results [2], which indicated no second peak in the curves of the rate of heat release of the surrogate RDF. The amount of material removed by pyrolysis and oxidation prior to extinguishment is approximately $68 \%$ and appears independent of sample thickness, its density and the imposed irradiance. This may be a result of high void fractions exhibited by the RDF studied, which inhibit the formation of a continuous layer of char during combustion. After ignition, the mass loss of RDF proceeds through three regimes: pyrolysis, pyrolysis and char oxidation (transitional regime) and char oxidation. The critical mass flux at extinction varies between 0.8 and $1.5 \mathrm{~g} \mathrm{~m}^{-2} \mathrm{~s}^{-1}$ for samples that extinguish in the transitional regime, and 1.5-1.9 $\mathrm{g} \mathrm{m}^{-2}$ $\mathrm{s}^{-1}$ for thinner and less dense samples for which the transitional regime is not well articulated. The scatter in the measurement of the critical mass flux is due to the difficulty in identifying the point of extinguishment of the flaming combustion.

The present results have confirmed our earlier findings that refuse-derived fuels may ignite rapidly, with the ignition accelerated by low thermal conductivity and low thermal capacity of these materials. The same factors also contribute to rapid fire growth just after the ignition. Following the extinction, RDF char display a long period of smouldering, responsible for high levels of $\mathrm{CO}$ and production of volatiles from deep seated fires. Such conditions may induce flashbacks and explosions during extinguishment of RDF fires.

\section{ACKNOWLEDGEMENT}

This study has been funded by the Australian Research Council and Delta Electricity.

\section{REFERENCES}

[1] Korzun, E.A., (1990) Economic Value of Municipal Solid Waste, Journal of Energy Engineering 116: 39-50. doi:10.1061/(ASCE)0733-9402(1990)116:1(39)

[2] Hirunpraditkoon, S., Dlugogorski, B.Z., and Kennedy, E.M., (2006) Fire Properties of Surrogate Refuse-Derived Fuels, Fire and Materials 30: 107-130. doi:10.1002/fam.894

[3] Hirunpraditkoon, S., "The Properties of Refuse-Derived Fuels”, PhD Dissertation, The University of Newcastle, Australia, 2003.

[4] Kashiwagi, T., Ohlemiller, T.J., and Werner, K., (1987) Effects of External Radiant Flux and Ambient Oxygen Concentration on Nonflaming Gasification Rates and Evolved Products of White Pine, Combustion and Flame 69: 331-345. doi:10.1016/0010-2180(87)90125-8

[5] Urbas, J., and Parker, J. (1993) Surface Temperature Measurements on Burning Wood Specimens in the Cone Calorimeter and the Effect of Grain Orientation, Fire and Materials 17: 205-208. doi:10.1002/fam.810170502

[6] Dlugogorski, B.Z., Wang, H., Kennedy, E.M., and Delichatsios, M.A., (2002) Testing of Gaseous Fire Suppressants in Narrow Channel Apparatus, Proceedings Halon Options Technical Working Conference, Albuquerque NM, USA, NIST Special Publication 984, 11 pp. 